\title{
Perfil Clínico E Epidemiológico Da Febre Amarela Em Santa Cruz Do Sul (Rs): Surto De 2009
}

\author{
Tabile, P.M.; Bassani, D.C.H.; Krummenauer, E.C.; Pereira, B.F.; Chaves, J.; \\ Carneiro, M.J.;
}

Apresentador: Patrícia Micheli Tabile

\section{Resumo}

Introdução: a febre amarela (FA) é uma doença infecciosa aguda, de curta duração, gravidade variável, causada pelo vírus da febre amarela, que ocorre na Américas do Sul e Central e na África. A transmissão ocorre pela picada dos mosquitos transmissores infectados em áreas urbanas (Aedes aegypti) ou silvestres (Haemagogus). As primeiras manifestações da doença são repentinas, com duração de cerca de três dias. Neste período surgem febre alta e pulso lento em relação à temperatura (sinal de Faget), calafrios, prostração, cefaleia, mialgia, náuseas e vômitos. A forma mais grave da FA é rara e geralmente aparece após intermitente sensação de bem-estar, quando podem ocorrer insuficiências hepática e renal, icterícia, manifestações hemorrágicas e prostração intensa. A vacinação é a mais importante medida de controle. O objetivo do estudo é avaliar o perfil dos pacientes com FA atendimentos em Santa Cruz do Sul. Método: estudo de casos de FA de 2009 que necessitaram de atendimento hospitalar na cidade de Santa Cruz do Sul, Rio Grande do Sul (RS) através da análise das fichas de notificação compulsória do Sistema de Informação de Agravos de Notificação (SINAN). Resultados: no ano de 2009 foram confirmados 10 casos de FA no município, sendo 7 (70,0\%) do sexo masculino.
A média de idade no ano analisado foi de 38,5 anos, variando de 22 a 56 anos. Não foi constatada nenhuma gestante no período analisado. Com relação à procedência, $9(90,0 \%)$ eram da zona urbana. $\mathrm{Na}$ análise da vacinação, apenas um $(10,0 \%)$ era vacinado contra a FA. O sintoma mais prevalente foi dor abdominal em $60 \%$ dos casos. Em nenhum dos casos analisados observou-se o Sinal de Faget. Dois dos pacientes $(20,0 \%)$ apresentaram sinais hemorrágicos evidentes e problemas na excreção renal. Na análise da avaliação da lesão hepatocelular, as enzimas Alanina Aminotransferase (ALT) e Aspartato aminotransferase (AST) estavam alteradas em 9 (90\%) dos pacientes. Já na observação da bilirrubina total e direta, ambas estavam alteradas em $80 \%$ dos casos. A hospitalização ocorreu em 7 (70,0\%) casos de FA. O óbito ocorreu em apenas $2(20,0 \%)$ dos pacientes. Conclusões: o perfil de pacientes acometidos por FA constatado no estudo concentrou-se em adultos jovens, do sexo masculino, sendo a grande maioria da zona urbana, e com alterações hepáticas importantes e sugestivas da forma grave da doença. Visualizou-se falha na principal medida de controle de FA, já que apenas um paciente estava vacinado.

\section{Referência:}

Tabile, P.M.; Bassani, D.C.H.; Krummenauer, E.C.; Pereira, B.F.; Chaves, J.; Carneiro, M.J.;. Perfil Clínico E Epidemiológico Da Febre Amarela Em Santa Cruz Do Sul (Rs): Surto De 2009. In: II Congresso Brasileiro de Medicina Hospitalar - II CBMH [= Blucher Medical Proceedings, vol.1, num.5] São Paulo: Editora Blucher, 2014. p.12

DOI 10.5151/medpro-II-cbmh-003 